\title{
Tajikistan Contemporary Poetry Themes
}

\author{
Gholam abas Nafisi, Mohammad Ali Davood Abadi Farahani \& Ali Sar Yaghoubi \\ m.nazanin67@gmail.com \\ Islamic Azad University, Arak, Iran
}

\begin{abstract}
Tajik poetry deviated from its mainstream with the victory of the communist revolution. The imposition of Russian language and the new communist literature made Tajik poetry take influence from the works of Russian romantic poets and have new themes. Meanwhile, it benefited from the ancient Persian poets and one can see the rhetorical figures such as metaphor, simile, conflict, pun, İhām, proverb, husn-i ta'lil (good reason), imagery and paradox in the works of Tajik poets. Additionally, Bĩdel's poem has also had a clear influence on the poetry of some contemporary poets. Tajik poetry is very close to the informal language of the people, and in these poems, we encounter words that are specific to the Tajik dialect. The first Persian she'r-e now (new poetry) in Central Asia was written by Sadriddin Ayni.

In Tajik poetry, we occasionally encounter with recurrences, the nostalgia of the missed glory, the oppression of the nation, and the unwanted fate of their ancestors. In these poems, the rely on emotion and content, and the epic and passionate tone prevail other poetic performances. The present study gives a general overview of the poetry of some Tajik poets.
\end{abstract}

Keywords: Poetry, Tajikistan, Tajik, Persian language

\section{Introduction}

If we regard Persian poetry and literature as a tree whose foliage and branches has reached all the lands of the Persian language people and the fruits of which are enjoyed by the children of these lands, we must admit that this fruitful ancient tree is rooted in the great land of the old Khorasan, which includes the modern Iranian Khorasan, and the vast territories today known as Afghanistan and Tajikistan. In days that there was no sign of civilization and culture in the present countries, people of those lands had culture and literature. Great poets such as Rudaki, Rumi, Attar, Sanai, Hafez, Saadi, etc. have grown up in those lands and every Persian speaking person is proud of them. They are poets that are still famous and their works have become more well-known over time so that they are known to more people in the world. The consistent words and content of the poetry of these great poets are such that even the translation of their works into other languages surprises the non-Persian speaking readers and increases their admirers. Today, with arguments about the modern and postmodern world, and due to the remarkable media facilities, languages will soon forget their old words and, instead, they will have more new words. But what is the reason for every-year memorials in different countries and the cost of these celebrations to commemorate those great poets, and, more participants attend these memorials and ceremonies every year? Is it not for no reason but the fact that the great sea of Persian literature is so much filled with spiritual gems and expensive pearls of words that the more the rhetorician divers search this sea the more jewels they find? The politically motivated world of today that has created new geographic boundaries does not want people to live together like the past, or the poets and writers write for their hearts and their people, and create literary and artistic works. There is 
no Iranian that reads Tārìkh-i Bayhaqī (Bayhaqi's History) book and is not influenced by the honesty of the author and great historian and does not feel to be close to him. There is no one who reads the life story of Hasanak the Vizier and does not blow in tears with the weeping of the author's pen.

The strong cultural and literary link between Iranians and countries like Afghanistan and Tajikistan is such that centuries of separation have not been able to disassociate their hearts, because no one can erase the love of the great people like Rudaki, Rumi, Abu Reyhan Biruni (Al-Biruni) and Abusa'id Abolkhayr from the heart of people of these lands. Therefore, in order to revive this cultural and historical affinity of people who share many common grounds and have loved the works of their great authors for centuries, an effort should be made to analyze and remind these respected commons to provide the ground for the affinity of the Persian speaking people and benefit from the richness of this reviving culture that has been cultivated for centuries among these nations, and not to let the geopolitical and political separations of the nations lead to their cultural and literary separations.

\section{Contemporary Tajik Poetry Content}

Tajik poets, following the example of Bidel's poetry, and enjoying the rhetorical figures of Indian poetry style, moved towards imagism in poetry. Although some poets like Muhammad Naqib Khan Tugrul Ahrari (1865 1919) considered themselves fascinated by Abdul Qadir Bidel Dehlavi and, as their poems show, followed him, but despite their talent, they did not succeed much because of mere imitation of Bidel's poetry. In this regard, Sadriddin Ayni says "Tugrul imitates Bidle, but like many of Bidle 's imitators, he has not succeeded in this pursuit. The talent of Tugrul was very complete and his imagination was capable of ascension. If he has not captivated his taste in imitating Bidel, and he knew himself well, he would have excelled in his own time" (Ayni, Sadriddin, 2016, pp. 41-409). Zafarkhan Jowhari is another Tajik poet who imitated Bidel and Sadriddin Ayni has spoken of him (Ayni, Sadriddin, 2016, p. 109). In addition to the effect of Bidel's poetry, Tajik poetry has been influenced by Russian romantic poets, too. Nevertheless, they still enjoy the ancient Persian poets and one can see the rhetorical figures such as metaphor, simile, conflict, pun, iham, proverb, husn-i ta'lil, and figures that are well-known today such as imagery and paradox in their poems. Tajik poetry, in comparison with Afghan poetry, has been less associated with Iranian contemporary poetry. Tajik poetry is very close to the dialect of the native people. In the works of poets such as Mü'min Qanoat, Bozor Sobir, Loiq Sher-Ali, and Gulrukhsor Safieva, you see a language spoken by the people on the streets. In these poems, we encounter words that are only available in the Tajik dialect (Mojib Mehrdad: December 6, 2009). According to Tajik scholars, the first Persian she'r-e now (new poetry) in Central Asia was written by Sadriddin Ayni.

When Tajik poetry was experiencing turbulence and indolence, few young people entered the field and created a new path for their language and culture, contrary to the current destructive stream. These were Mū'min Qanoat or the "Nima of Mian Roodan", who initiates this trend, and the Bozor Sobir and Loiq Sher-Ali who followed him. These are the first people who breathed a new life in the dead body of the Tajik poetry and created hope for people who were drowning in a foreign culture. Replying to those who called the Persian language three different names with wrong intentions, Mū'min Qanoat says

\section{Either you call it Farsi or Dari \\ Say what you say \\ Or you call it the good words of coquetry \\ Say what you want \\ For me, it is only the mother tongue \\ This is like the breast milk \\ There is no other thing to liken it to \\ Since it is the mother's love.}

Bozor Sobir also expresses his objection to the current situation with language. His "Zaban Madari" (mother tongue) poem expresses the painful history of the Tajik people.

Whatever it had in this world, it lost It had Balkh and Bukhara, it lost It had a great tradition and the Court of Justice, it lost 


\section{It had the throne of Saman, it lost ...}

The young poetry of present Tajikistan breathes with full glory in the Persian language territory, and it has a great contribution to this process. Poets such as Siavash, Rostam, Farzaneh Khojandi, Ali Ajami, Soroush Esfandiar, Dara Nejat and others are known by their works in the entire Persian language territory. On the other hand, Tajiks also know the poems of poets such as Bahmani, Monzavi, Salman Harati, Ali Moalem, and Najme Zare in Iran, and Parto Naderi, Sami Hamed, Qahar Assi, Seyyed Reza Mohammadi, Sharif Sa'idi and others in Afghanistan. This reveals a promise for the re-establishment of a major language territory.

\section{Language and Literature as the Identity of Tajik People}

In the introduction to the book "Sample of Tajik Literature" on the importance of the work of Sadriddin Ayni, Dr. Ali-Asghar Sherdost writes "Sample of Tajik Literature was the tip of the iceberg, although prepared in a hurry and quickly, it was able to silence the tumult of the mob that was going to deny the national, ethnic, and cultural identity and the ethnic language of Tajiks, and bring them to their knees. That's why Tajiks still consider the "Sample of Tajik Literature" as the proof of their identity and they appreciate it and are proud of it (Ayni, Sadriddin: 1385, p. b).

Sadriddin has a long Tarji-Band that is full of curses, curses on the oppressors who gain power by slaughtering people and commit numerous crimes to keep their power. This throne, instead of bringing peace and security, causes the nation to be miserable. In this poem, Sadriddin curses the oppressors from the bottom of his heart and fully expresses his hatred.

Such curses and complaints of the time clearly indicate that the noble Tajik people have gone through many hardships and lost many lives for the sake of their love and interest in the language of their ancestors, i.e. Persian language. As a result, now that they have found a small relief and have survived the former Soviet communist regime by the independence of the Tajik countries, and have been able to establish relations with their neighboring countries who speak the same language, it is not unlikely that they will need to communicate with the people who have spoken their language for a long time in order to rejoin their historical past, and benefit from the eternal sea of Persian language and literature (Sherdost, 2010).

\section{Bozor Sobir}

The professor Bozor Sobir, along with Mū'min Qanoat and Loiq Sher-Ali, were the founders of the literary-cultural movement after years of forgetting and silence among Tajiks. The obvious difference between Bozor Sobir and others is that when other poets talk about their homeland, they also a little consider the Soviets, while Bozor Sobir wanted to draw the true borders of his country begun at the start of alienations for the Tajiks in his poetry. In his poem, he does not speak of any country but Tajikistan, and Tajikistan appears with another manifestation. The beautiful nature of Tajikistan has less found its true and elegant appearance in other poetries than in his. In Tajik poetry, these figures are referred to as wisdom symbols and glorious and liberating myths for future generations.

Bozor Sobir's poetry was written in the same language of Tajik poetry at that time. Tajik poets have paid less attention to the language itself and its structure in their poetry. The images are so simple that they cannot be easily detected in these poems. Tajik poetry is more reliant on emotion and content and the poet forgets the language when writing the poem. Tajik poetry is epic. Tajik accent is naturally rigorous and is the most favorable bed for epic poems.

The poems of Sobir are tremendous, especially when he wants to make a show. In Tajik poetry, you see very old words along with informal words. It is hardly possible to disclose the boundaries of formal and informal languages in these poems. This fact is both evident at the lexical and the syntactic levels.

The love poems of Bozor Sobir are unique. In his poems, the beloved sometimes has a natural manifestation, or in other words, it is a 
part of Tajikistan's beautiful and diverse nature or vice versa, nature appears in the form of a beloved in his poem.

In his poems, we see impressive images that are completely new and defamiliarize our aesthetic sense, and art has no duty but eliminating the dust of familiarity from the eyes of the beholder:

\section{Remained like an anonymous island In the midst of the sea of ancient memories The homeland, my love, your youth The homeland, my love, your youth (Fire leaf, 1984, p. 11).}

Bukhara is a sore wound in Tajik poetry, a separated part of Tajiks' body that they always look at it with regret:

The land of my poetry is not a grave of words

It is the durability of the mountains and deserts of my homeland

My alive native language

Is the language of spring thunder and rain

My lips are opened to poems by springs

And my heart by cascades

Not line by line, but stream by stream to my book

Has reached the water of the sea of Zarfeshan (Kofi site, 2009).

\section{Loiq Sher-Ali}

Professor Loiq Sher-Ali is a major Tajik poet that had a new perspective. With his innovations is rhyming schemes, and with his social-political-literary thoughts, he created a new era in Tajik literature. He attracted the attention of literary people by writing the poem of "The Name" published in 1959 in the influential literary magazine of "Red East". In Loiq's poems, one can see the grief of loneliness and the perplexity of his countrymen. The adventures that he had throughout his life have been very effective in expressing his feelings. When he contemplates on his past, he is worried about it and says:

My childhood passed in solitude

By harvesting and harvesters

With a handful of clusters

It passed across the field
Attention to nature, mountains, and the sea are observed in the poems of other Tajik poets, too. Sometimes the poet, by comparing himself to one of the manifestations of nature, expresses the words as if he is talking to a living creature (personification). In this conversation, the poet reveals his intention to express his inner feelings, as if he does not find someone to talk to.

The themes of Loiq's poetry are diverse, from personal issues to social issues, to return to the past and to be proud of historical and contemporary characters, descriptions of the land and the peasants, etc. The poetry of Loiq is first of all about human self-knowledge, which is in search of himself, his origin, his past, and the perception of his life and time, and it is because of this effort for selfknowledge that the poet talks about the ancient history of the nation and its great scholars and scientists, and recounts the current problems and sorrows of the nation (All Poems, 2004, p. 5).

Loiq's poetry links the contemporary poetry and the past Tajik Persian poetry. Generally speaking, Loiq is a traditionalist, but his new poetry is the common language of the people of his time. This is why he is popular among his compatriots. While adhering to the principles of traditional poetry, he has written many poems in the new style. His poetry expresses his talent and innovation so that with the use of appropriate rhetorical figures, he has been able to distinguish his poetry from other poets of his time. New poems of Loiq, which has played a significant role in the evolutionary process of Tajik contemporary poetry, is mostly influenced by the Nimayi poetry of the poets of Iran. Nevertheless, he believed that Nimayi poetry would not have a future in Tajikistan since the taste of the Tajik people would not be satisfied by the rhymeless nature of new poetry. Loiq's new poetry is not written completely in accordance with the principles of Nimayi poetry. He mostly writes Charpareh and changes the length of the hemistiches, bringing his poetic thoughts to his audience. The Iranian Nimayi poets who had significant supporters in Tajikistan include Nader Naderpour, Fereydoon Tavaloli, Forough Farrokhzad, Khanlari, Sayeh, and 
Kasraei. Present poets of Tajikistan have benefited greatly from their poems. Although Loiq is inspired by the poems of the poets of Iran, his creativity and art are completely visible in his new poems.

About the inspiration of Loiq Sher-Ali, Professor Alam Jan Khajeh Morad says "The inspiration of Loiq by other poets of the twentieth century in Iran has not been uniform in different periods of his poetry writing. In creating a series of his poems called "Madar Nameh" (the book of the mother) he was creatively influenced by Iraj Mirza, and in writing Ghazal by Rahi Mo'airi, Shahriar, Simin, Akhavan-Sales and the like. The poem of "Kaveh weeping on the death of his seventeen sons" by Loiq reminds you of the AkhavanSales's poem of "for this sadness, not only my eyes shed blood".

However, unlike the current poetry of Tajikistan, which in its entirety engages in national issues, Loiq's poetry is not free of individual concerns and philosophical thoughts. Loiq sometimes writes about love, with its earthly and everyday meaning, human life and relationships, and life and death. He considers death a reason for rebirth and motivation of dynamism in the ongoing route of life (Elegy of death, p. 35).

Loiq's poetry is content oriented, like the poems of Mū'min Qanoat and Bozor Sobir, a poem that is filled with love for Tajikistan and the historical pains of its people.

Loiq is powerful in writing Ghazals, too, and his contemporaneous poets have used classical forms less than him and have been less successful. He has written Ghazal, Dobayti, Ruba'i (quatrain) and Charpareh, and there are undoubtedly spectacular samples among his works, which are rare in Tajik poetry and especially in these formats. However, Loiq has shown his capabilities in Do-bayti and Ruba'i more than other formats. His Ruba'is cover the subjects of worldliness, caring for happy moments (carpe diem), and everyday romantic issues. As the love of a mother, he has well-developed the torn-apart homeland and the hope for a reunion of culture in this short format. No other contemporaneous poets equate him in terms of quantity and quality of writing Do-bayti and Ruba'i. Many of these Do-baytis and Ruba'is are retold by Tajiks and are sang in ceremonies.

\section{Gulrukhsor Safieva}

Gulrukhsor is the most famous female poet of Tajikistan. This reputation is due to both her sweet poetry and her multifaceted character as a poet, novelist, and politician. Ms. Gulrukhsor Safieva is a popular Tajik poet that published her first poems in 1962 in literary magazines. She continued to work in the press as the head of the press office of the Central Committee of Tajik Komsomol and the editor of the Pianar newspaper in Tajikistan and was promoted to the Secretariat of the Tajik Writers' Association. "Shelter in the shade", "Green women of spring" and "Hardships of death" revealed another literary aspect of Gulrukhsor and introduced her as a successful novelist to the contemporary Tajik novelists and novel readers. The poetry books of Gulrukhsor were published one after the other and each one more successful than the previous one. She introduces Hafez and Bidel as her first degree masters and considers her poetry more closely related to the poetry atmosphere of these two great poets. So far, two cassettes of poetry reading have been published with the voice of Gulrukhsor: "Alone woman's streets" and "Tears of typhoon", which still have a lot of popularity among Tajik poetry lovers (Surah Mehr, No. 57).

\section{Theme and Content}

In Tajik poetry, you see very old words along with informal words. It is hardly possible to disclose the boundaries of formal and informal languages in these poems. This fact is both evident at the lexical and the syntactic levels.

The hardships of the life have made Tajik poets, who have had many cultural, historical and national concerns, to use all their energies to express their unspeakable words in a simple way. This is why, according to Mojib Mehrdad, "The Tajik poet, when speaking of his historical pains, uses the language recklessly, and he does not fear that this poem lacks an artistic aspect and anything that gives it an artistic 
value. Tajik poetry is a sensual poetry, one that blends the nature of the homeland and the cultural-historical homeland with nostalgia, quarrel, and complaints to make the body of Tajik poetry. The Tajik poet always feels a vindictive and envious enemy waiting behind the gates of his culture. He has inherited this feeling from his risky history" (Tajikam, May $29,2010)$. Tajik poetry is full of awakening themes, and the poets were willing to maintain their enormous culture at any cost to escape the domination of foreigners. Therefore, "during these years, the Tajik poet sees that his culture, which has great scholars like Ferdowsi, Maulana and Saadi, is ill-treated, his only homeland is divided, his great language loses its authority, and he can do nothing" (Ibid.). Nonetheless, Tajik poetry has a beauty that influences Persian speakers. As the Tajik poet Mojib Mehrdad says "Tajik poetry has beauties that have a special refreshing and sweet taste for the Persian speakers. Tajik poetry, unlike the poetry of Iran and Afghanistan, is the poetry of content, i.e poets pay attention to the theme in each poem, instead of dealing with transient moments and shortcuts and transient inspirations. Although we see this style in Iranian poetry in the works of Nima and his successors, and in the poetry of Afghanistan in the works of poets such as Vasef Bakhtari, Latif Nazemi, Parto Naderi and Siah Sang; Akhavan is the epic writer and storyteller. However, Tajik poetry, unlike the poetry of Nima and Akhavan, have become content-centered in accordance with Russian poetry and poets such as Pushkin, Lermontov, Sergei Yesenin, Mayakovsky, Akhmatova, and Mandelstam, since Tajik poets had an organic link with the Russian poetry through the Russian language, in which they were all fluent. For this reason, whether Mū'min Qanoat, Bozor Sobir or Loiq Sher-Ali, all have written poems like The Bronze Horseman by Pushkin, Letter to My Mother by Sergei Yesenin, A Cloud in Trousers by Mayakovsky, etc. (Ibid.). What is repeated throughout the poems of all the poets of Tajikistan, alongside the expression of the suffering of the separated homeland, and the lost history, especially in times of the Russian rule, is the matter of love for mother, which is one of the central themes of Tajik poetry. Mother is very much honored by the Tajiks. Tajiks consider their homeland the same as a mother and their mother as
Tajikistan and consider no difference between the two. Tajik poetry, from the perspective of the Persian speakers of Iran and Afghanistan, is weak in terms of language usage, which is quite right, but the problem arises because Iranians are less familiar with the syntactic structure and the wording of the Tajik dialect resulted from forced geographical separations. This problem particularly occurs when Tajiks remove any gap between their informal language and their literary language in previous generations. If we are familiar with these issues, many of these phonetic and syntactic weaknesses would not come up to us as flaws and will double the pleasure we receive by reading these poems. In any case, what is certain is that the poetry language of the second and third generations, using the possibility of new communication with Persian sources and other Persian speakers, has come closer to the standard Persian language. However, the specific sweetness of reckless use of the language, which was mixed with rich native resources in previous generations, is less pronounced in the language of the new generation of poets. Tajiks have encountered many injuries through especially those inflicted on them by the rule of the Communist Party, who intended to take away their identities and to eliminate their thousandyears-old culture and literacy. This has made Tajik poets, who have had many cultural, historical and national concerns, to use all their energies to express their unspeakable words in a simple way. This is why, according to Mojib Mehrdad, "The Tajik poet, when speaking of his historical pains, uses the language recklessly, and he does not fear that this poem lacks an artistic aspect and anything that gives it an artistic value (Wonderful climate of Tajik poetry, October 2009).

\section{The Decline of Tajik Poetry}

About the superiorities and weaknesses of contemporary Tajik poetry compared with the poetry of other Persian poets, Qanoat says "Iranian scholars also say that the current poetry of Tajikistan is superior to the poetry of other Persian poets in terms of its theme, meaning, and realism. There is a defect in Tajik poetry, however, that is related to the rules of Persian poetry, namely, prosody, rhymes, rhetoric, and perspicuity. Perhaps our poets 
have benefited less from these language arts. That is because in their poetry, purpose and meaning are realistic, but the decoration of that particular meaning is not the same meaning, that is why the rhetorical figures are somewhat weak and old". Tajik poetry requires a thorough review. However, according to Qanoat "Tajik poetry requires a comprehensive review after the independence of Tajikistan ..."

Dr. Sherdost has divided the themes of Tajikistan poetry in the "Perspective of poetry of Tajikistan" book as follows:

a. poems that have a historical-national background and they talk about the history of the Tajik people, their culture and native language, and relations with Iran. In some of these poems, the poet searches for his lost identity with the help of the historical memory. Those patriotic poems written in praise of Tajikistan or Iran are also in this group.

b. Mother and wife are also commonly-used topics of contemporary Tajik poetry. Almost every Tajik poetic book has some poetry on these subjects. Some poets, such as Loiq Sher-Ali, have a poetic collection on this subject.

c. Childhood is also a constant theme of the works of every poet. The focus of contemporary Tajik poets is on the same issue, too.

d. War and Peace are other themes of Tajik poetry. Since Tajikistan, like other Soviet republics, itself was part of a country that was one of the main fronts of the world war, many of its poets have written poems about the devastation of the war, the heroism of the Soviet troops, and the propitiousness of peace. Many of the featured poems are written on the same subject. "The angel of Stalingrad" by Mū'min Qanoat is one of them.

e. Tajik poetry also has a lot of romance. Love in Tajik poetry - like the poetry of most nations of the world - is a feature that most poets have written about.

f. Nature is one of the old themes of Persian poetry. Following this tradition, the contemporary Tajik poets have also depicted nature in their poetry. g. The political-social themes of Tajik poetry can be explored in two branches: The period before the collapse of the Soviet Union and the post-independence period of Tajikistan. In the first period, poems are full of praise, while the protest is formed in the second period, of which Bozor Sobir is the most prominent representative. Based on the works studied, Bozor Sobir has poems in praise of the Soviet Union in the first period. Although there is protest poetry in the first period and praise poetry in the second, they have no definitive nature.

h. Although the ethical advice is an old theme in Persian poetry, it is presented in contemporary Tajik poetry both traditionally and in other ways.

i. Due to the conditions, the religiousmystical poetry is still weak, but due to its remarkable start, we will see the flourishing of this branch in the future" (Sherdost, Ali Asghar, 2010, pp. 83-84).

Recalling the magnificent history of the

Tajik people and the oppression that Tajiks have come across in history is the source of many poems. Among Tajik poets, one cannot find anyone who has not written poems about it. We will find some spectacular examples in the works of the Sobir Bozor. In several poems, Sobir speaks of the glory of the Samanid era and the grief of his oppressed people.

In a poetry, we find the poet at the side of the Bukhara wall, putting his lips on the lips of the cracks of the wall, stroking its shoulders, and writing a grieving poem (Ibid, 83-85).

After the independence of Tajikistan, culture and literature were also liberated from an ideological fence. Contemporary poets have no more limitations in the open atmosphere and the literary environment filled with ups and downs. The poetry of independence era moves back to its root, foundation, and initial origin, and great poets such as Rostam, Siavash, Khojasteh Sayyad, Farzaneh, Soroush, Esfandiar, Afagh, Azar, Vares, Dolat Rahmanian and dozens of others bear the great duty of being a poet, who tie together the past and present of Persian Tajik poetry is in Central Asia.

Sadriddin has a long Tarji-Band that is full 
of curses, curses on the oppressors who gain power by slaughtering people and commit numerous crimes to keep their power. This throne, instead of bringing peace and security, causes the nation to be miserable. In this poem, Sadriddin curses the oppressors from the bottom of his heart and fully expresses his hatred. Here is the last clause of the TarjiBand:

Oh God! Destroy that house of oppression

Oh God! Bury that court of oppression

Oh God! That throne that made us miserable

Shatter it and raise it to the ground

Such curses and complaints of the time clearly indicate that the noble Tajik people have gone through many hardships and lost many lives for the sake of their love and interest in the language of their ancestors, i.e. Persian language.

Bozor Sobir has a poem in which there are references to the history of its ancestral land, it has images that affect the reader:

\section{Like the blood of the homeland \\ From the neck of Nizam al-Mulk \\ Drop \\ By drop \\ We dripped}

The fluctuating history of the Tajik people is more reflected in the works of Loiq Sher-Ali and Bozor Sobir. In the poems of these two, the bitter fate of the Samanids is depicted for the readers dolorously. In the following poem, Bozor Sobir addressed himself, whose tone is very sad. On the other hand, the sarcastic tone of the poem is obvious. The cry and adjuration of Bozor are well heard between the lines of this poetry:

... Shame on me, Shame on me, Shame on me ...

I was before

But I was not

Or what was I

... My face is in that sad image that pours sadly

From Sistan's minarets and towers

My grief is in those stones that are silent and crying

\author{
In the tomb of Rudaki and Samanids \\ I made Bamian \\ I processed Kafian \\ I lost Kafian \\ The throne of Dara was in my way, I ruined \\ it \\ The treasure of Qarun was in my hand \\ I wasted it \\ I considered it a piece of straw and a bunch \\ of dirt \\ Shame on me, shame on me \\ What have I done \\ I expelled Avicenna from the honorable \\ Bukhara \\ I threw Al-Tirmidhi in the Amo river last \\ night \\ I shed the blood of Nizam al-Mulk \\ Even I shed the blood of our land ...
}

Gulrukhsor also refers to the resistance of Tajik people against the life events, and uses the word of $T a j$ (crown) to show the immortality of the Tajik people:

Fate has overthrown many kings with crowns

And has made kings beg the beggars

So many Qaruns has spoiled their life

But Tajik peoples have always worn the crown

They have been looted many times but never looted others

(Selection of poems by Gulrukhsor, p. 57; Landscape p. 90).

\section{Tajik Poetry Stylistics and Aesthetics}

The review of contemporary poetry in Tajikistan, will not categorize the poems written in this era as classified in typical stylistics of Iran into the style of poets based on the place they lived in. Although many scholars believe that the classification of different poetic styles in Iran was not based on a correct method, they themselves did not provide the method they considered correct.

Due to the political and historical changes that took place in Tajikistan in the contemporary century which was going to eradicate the Persian language, poetry did not find good conditions to follow its normal course and flourish as in Iran. Therefore, the categorization of poetry periods in Tajikistan 
and Afghanistan are remarkably different from the situation in Iran.

This is because the style of poetry in contemporary Tajik literature have not followed a correct course. If we want to give a correct definition of the style of this period, we should say that we can find the trace of every style in Tajik contemporary poetry. That is because the fighting poets, in order to save their Persian poetry and language they have used the word to express their goal which was the struggle to keep the Persian language alive, regardless of the texture of the words and use of rhetorical figures. As a result, poetry has sometimes been transformed into slogans without any specific features.

Many of the poems of this period are written in the same old forms of Qasida (ode), Ghazal, Masnavi, Do-bayti, Qit'e, and sometimes Musammat. We will describe each of them separately.

\section{Qasida}

This form, which has been used extensively in ancient poetry, has not attracted much attention in contemporary Tajik poetry. As a result, no Qasida writing poet has emerged in Tajikistan during this period. As Bidel says:

\section{Neither Ghazal nor Qasida will remain after us \\ Only two or three drops of tears from the pens will remain}

In addition to the factors that made the poetry of Tajikistan stay away from Qasida, one of the other factors was the language after the October Revolution of this country, which attributed the perfection of the language of poetry to the bourgeoisie and reactionary, and Qasida could not survive such circumstances. however, there are some long poems by some poets that can be considered as some kind of Qasida. The political Qasida by Loiq with the following beginning lines is one of them:

The land of stones, and we have no fortress Every one of us a warlord, and we have no leader...

(A selection of poems by Loiq, 1995, p.
179).

\section{Conclusion}

From the review and comparison of the themes of contemporary poetry of Afghanistan and Tajikistan, it is concluded that the Persian poetry of Afghanistan is far superior to Tajikestan poetry in terms of sophistication and consistency of the word and the use of rhetorical figures in the classical style. and the works of Iranian poets are far superior to that of the two Persian-speaking neighboring countries. These superiorities have been made due to their specific political and geographic conditions. Because over the past century there has been more unrest in those countries, and the opportunity for cultural, literary, etc. development is only obtained when the people of the country are at peace over the years. This peace has been less available in Afghanistan and Tajikistan. Moreover, the distancing of these countries from the Iranian Persian language and their particular conditions have caused the dialects to differ, and this difference is more evident between the language of the Tajik people and Iranian people. Obviously, Tajik and Afghan dialects are different, and there are words and phrases in these languages that are less available in the Iranian vocabulary. For instance, there are words specific to the people of Tajikistan that either do not exist in the language of Iranians or they have a different meaning. The names of the new instruments are different in Iran, Tajikistan, and Afghanistan.

\section{Ghazal}

Tajik poets have tried to keep the form of Ghazal alive in every situation. In the Ghazals of first-generation poets, the lyric, classical, and political languages were parallel. The Ghazal of "Tajik song" by Sadriddin Ayni is one of them. Some of the Ghazal writers of this era, along with political poetry, have tried to improve lyric Ghazal (real Ghazal), too, and relying on the rich Persian Ghazal history, and being influenced by the Indian style, they have created beautiful, yet simple Ghazals. The impact of Bidel's style on Tajik poetry, especially in Ghazal, is sometimes quite obvious. 


\section{References}

Kagashah Qajar, Abdul Qadir Khan, 1373 "In the study of the Tajik word" in Tajikistan on the route of collecting and researching Mirza Shakurzadeh Tehran: Al-Hadi

Investigation, Mohammad, 1356, Review of Today's Literature in Iran, Fourth, Tehran, Amir Kabir,

Babajan Ghafurov, 1377, Tajik Monday, mysticism.

Market Publishers, 1984, Fire Book, Monday, Sufism.

Bahar, Mohammad Taghi, 1369, Stylistics, Fifth, Tehran, Amir Kabir.

Beyhaghi, Mohammad bin Hussein, 1368, Beyhagi date, Khalil Khatib leader, Tehran

Peyman, 1992, collection of poetry, Monday, Adib.

Javid, Abdul Ahmad, 2006 "A Few Things About Tajiks" in Tajikistan on the Road of History, Tehran, Alhadi

Dai al-Islam, Mohammad Ali, 1364, The Culture System of Hyderabad, Dekan, Offset, Tehran

Encyclopedia of Persian Literature, 1996, under the direction of Hassan Anousheh, C 1: Central Asia, Tehran; Ministry of Guidance

Sadiqi Editor, Dr. Seyyed Mohammad, 1385 TAT and Tajik, quoted from Tajikistan on the path of history, subjectivism, turgel "2006 Tajik word in the works of the past" in Tajikistan on the route of Tehran, alHoda

Pourvood, Apetist: Tafsir and Nature, from the publication of the Association of Iranian Zoroastrians in Iran, Lak Bombay

Professor Hammam, 2006, Tajik writer, quoted by Tajik in the course of history, Tehran, al-Hoda
The Encyclopedia of Tajik Literature and Arts, vol. 1, p. 82; d. Islam, Second Edition

The same, c 1, p. 82; d. Islam, Second Edition

Friend, Jalil, 1374 AH, Avesta: The most ancient hymns and texts of Iranian report and research, Tehran

Divan Jahri, 1986, quoted from the perspective of today's Tajikistan, Alhadi

Professor Hammam, 2006, Tajik writer, quoted by Tajik in the course of history, Tehran, al-Hoda

Sajjadiyeh, Mohammad Ali, 2006, "Again Tate and Tajik" in Tajikistan on the path of history, Tehran, Alhadi.

Sa'dizadeh Samarghandi, Saeed, "From the Political History of Tajiks in Afghanistan" in Tajikistan

Sidi, Mahdi, 2006 "Tajiks and Tajikistan to Mogul attack in Tajikistan on the path to history, Tehran, Alhadi.

Shukurzad, Mirza, 1380s, Aryans and Plateau of Iran, Collection and Research, Tehran Soroush

Shukurov, Mohammad Jahan, 1997 "Literary Traditions of Sadr al-Din-e-Ain and its Stages", Journal of the Academy, Year 3, Sharvardost, Ali Asghar, 2010, Tajik Landscape,, Tehran, International Islamic Theatrical

Shirali, Laig, 2004, Poetry General, Tehran, Farsi Tajik Institute of Culture,

Shakouri, Mohammad Jayan, "Some of the history of the division divided by force of the ax" in Tajikistan on the path to Shamiza's history,

Shirali, Laig, 2004, Poetry General, Tehran, Farsi Tajik Research Center

Saber, Market, 2010, The Perspective of Poetry in Tajikistan, Tehran, Alhadi

Saber, Market, 1999, The Poetry of Shedding 
Blood, by the Passion of Rahim Muslims Ghobadiyani, Tehran, Al-Hoda

Seddiqi, Jalal al-Din, 2006 "Tajikistan, Tajik in the path of history, Tehran, Al-Hoda.

Safa, Debihallah, 1356, History of Literature in Iran, Fifth, Tehran, Amir Kabir.

Saber, Market, 1999, The Poetry of Drowned Blood, by the endeavor of Rahim Musliman Ghobadiyani, Tehran

Aliyev, Abbas, 2006, "Defending the Truth" in Tajikistan on the path of history,

Omarzadeh, Mohsen, 1385 "Tajik frontier is Tajik language" in Tajikistan on the path of history, Tehran, al-Hoda

Aini, Sadr al-Din, 2006, Sample of Tajik Literature, Taharin, Cultural Heritage Organization.

Muslims of Ghobadiyani, Rahim, 1376, Persian language and literature in Farrood, Tehran;

Muslims of Ghobadiyani, Rahim, 1377 "Allameh Eini and Tajik Farsi Literature": Special Issue, Literature, Art, Environment, Tabatabai, Master Mohammad, 1376, About Tajik and Words, Tajik on the Way of History, Allah, Muslims, Ghobadiyani, Rahim, Language And Persian Literature in Farrood, Tehran,

Muslims of Ghobadiyani, Rahim, 1385 "Nowruz in Ghobadian" Bukhara, 3rd year, 4th Alhadi First edition

Mehrdad, Spring, 1362, Research in the mythology of Iran C 1, Tehran, Awareness.

Muhammad the King of Bin Ghulam Mohiyeddin Shad, 1363 Sh, Anandarq, Farsi Farsi Culture Mohammad Dehir Esmaili Tehran, Zavar

Maharawi, Yahya, 1377, Proceedings of the Proceedings by Mahmoud Tavousi "Tajik and Tazik" Shiraz, Navid.
Matin-Doost, Ahmad "Current Iranian Languages in Tajikistan" Parsi Language Year 5 (2) (Summer 2000)

Tabataba'i Environment, Mohammad, 2006 "About the Tajik and Tata Names" in Tajikistan in the History of Tehran, Alhadi

Mousavi Garmaroudi, Ali, 2009, from Shagha to Sadr, Second Edition, Tehran, Ghadiani Publishing.

Mirahmadi, Maryam "Tajik folk and Tajik culture in Central Asia" in your Tajik history.

Nafisi, Ali Akbar, 1355, Nafisi Culture of Tehran, Khayyam

Nobahar, Abdul Ghaith, 2006, "Tajiks of Afghanistan" in Tajikistan on the path of history, Tehran al-Hoda

Nafisi, Saeed, 2006, The article "My Clean Land", Tajikistan in the Course of History, Tehran, Allah 